FedUni ResearchOnline

http://researchonline.federation.edu.au

This is the author's accepted version of the following publication:

Guinea, A., Playà, E., Rivero, L., Himi, M., Bosch, R. (2010)

Geoelectrical classification of gypsum rocks. Surveys in

Geophysics, 31(6), 557-580.

The version displayed here may differ from the final published version.

The final publication is available at:

http://doi.org/10.1007/s10712-010-9107-x

Copyright $@$ 2010, Springer Science+Business Media B.V. 


\title{
GEOELECTRICAL CLASSIFICATION OF GYPSUM ROCKS
}

\author{
Ander Guinea $^{1 *}$, Elisabet Playà ${ }^{1}$, Lluís Rivero ${ }^{1}$, Mahjoub Himi ${ }^{1}$, Ricard Bosch ${ }^{2}$ \\ ${ }^{1}$ Departament de Geoquímica, Petrologia i Prospecció Geològica. Facultat de Geologia, Universitat de Barcelona \\ (UB). Martí i Franquès s/n, 08028 Barcelona, Spain. \\ ${ }^{2}$ Departament d'Enginyeria Elèctrica. ETSEIB, Universitat Politècnica de Catalunya (UPC). Diagonal 647, 08028 \\ Barcelona, Spain. \\ E-mails: anderguinea@ub.edu; eplaya@ub.edu; Irivero@ub.edu; himi@ub.edu; bosch@ee.upc.edu \\ *Corresponding author: Phone number: +34 9340311 65. Fax number: +34 934021417
}

\begin{abstract}
Gypsum rocks are widely exploited in the world as industrial minerals. The purity of the gypsum rocks (percentage in gypsum mineral in the whole rock) is a critical factor to evaluate the potential exploitability of a gypsum deposit. It is considered than purities higher than $80 \%$ in gypsum are required to be economically profitable. Gypsum deposits have been studied with geoelectrical methods; a direct relationship between the electrical resistivity values of the gypsum rocks and its lithological composition has been established, with the presence of lutites being the main controlling factor in the geoelectrical response of the deposit. This phenomenon has been quantified in the present study, by means of a combination of theoretical calculations, laboratory measurements and field data acquisition. Direct modelling has been performed; the data have been inverted to obtain the mean electrical resistivity of the models. The laboratory measurements have been obtained from artificial gypsum-clay mixture pills, and the electrical resistivity has been measured using a simple electrical circuit with direct current power supply. Finally, electrical resistivity tomography data have been acquired in different evaporite Tertiary
\end{abstract}


basins located in North East Spain; the selected gypsum deposits have different gypsum compositions.

The geoelectrical response of gypsum rocks has been determined by comparing the resistivity values obtained from theoretical models, laboratory tests and field examples. A geoelectrical classification of gypsum rocks defining three types of gypsum rocks has been elaborated: a) Pure Gypsum Rocks (>75 \% of gypsum content), b) Transitional Gypsum Rocks (75-55 \%), and c) Lutites and Gypsum-rich Lutites ( $<55 \%)$. From the economic point of view, the Pure Gypsum Rocks, displaying a resistivity value of $>800$ ohm.m, can be exploited as industrial rocks. The methodology used could be applied in other geoelectrical rock studies, given that this relationship between the resistive particles embedded within a conductive matrix depends on the connectivity of the matrix particles.

\section{KEY WORDS}

Gypsum rocks; electrical resistivity tomography; lutites; theoretical models; laboratory test; field examples. 


\section{INTRODUCTION}

Gypsum is a common mineral in the evaporite rocks; it is deposited both in marine evaporative basins and lakes. Gypsum is a dihydrated calcium sulphate $\left(\mathrm{CaSO}_{4} \cdot 2 \mathrm{H}_{2} \mathrm{O}\right)$, being the most abundant within the sulphate minerals. The gypsum rocks are dramatically affected by diagenesis; primary (depositional) gypsum is transformed to anhydrite $\left(\mathrm{CaSO}_{4}\right)$ when buried (or in sabkha environments). The anhydrite deposits rehydrate again and transform to gypsum rocks when exposed to weathering processes (secondary gypsum rocks). In general, gypsum rocks are mainly composed of gypsum, accompanied by lutites (clays and microcrystalline carbonates); as minor minerals, celestite, quartz, anhydrite, and glauberite can be present.

Gypsum rocks are widely exploited in the world as industrial minerals, being used as ornaments (gypsum alabaster), drywalls, plaster of Paris, fertilizers, soil conditioners and in Portland cements, among others. Spain is one of the greatest gypsum producers of the world and the European exporter leader, with an annual production of $13 \mathrm{Mt} / \mathrm{y}$ and estimated resources of $60 \mathrm{Mm}^{3}$ (Regueiro et al. 2004). The purity of the gypsum rocks (percentage in gypsum mineral in the whole rock) is a critical factor to evaluate the potential exploitability of a gypsum deposit. It is considered than purities higher than $80 \%$ in gypsum are required to be economically profitable in the case of conventional building plaster, and higher than $92 \%$ for plaster of Paris (Cerulla 1997; Bonetto et al. 2008).

Electrical resistivity tomography (ERT) is a geophysical technique which has been successfully used to study gypsum deposits (Lugo et al. 2008; Guinea et al. 2010). With ERT, the apparent electrical resistivity of the terrain is measured by nailing electrodes in the soil and injecting a DC current through two electrodes; the difference of potential between another two electrodes is measured. With an inversion routine, the data acquired in the field are processed and a real resistivity distribution of the subsurface is obtained. This method is non-invasive and it has a relatively low cost compared with high cost drilling projects which are usually performed to investigate gypsum deposits. 
The electrical resistivity values of gypsum rocks were studied by Guinea et al. (2010); a direct correlation between the conductivity of the rocks and the gypsum content was defined. A strong influence of the presence of lutite in the geoelectrical response of gypsum rocks was shown. The purest gypsum rocks ( $>90 \%$ in gypsum content) have resistivity values higher than 900 ohm.m. The presence of lutites within gypsum decreases these values to less than 100 ohm.m in the most impure rocks ( $<10 \%$ of gypsum). The resistivity values of lutites are well known to be 1-20 ohm.m (Orellana 1982; Martinez et al. 2009). Nevertheless, the relationship between the lutite and gypsum minerals has not been quantified yet.

The main objective of this study is to establish a geoelectrical classification of gypsum rocks on the basis of their mineralogical composition (mainly lutite and gypsum percentages) and their electrical resistivity values. This classification would properly interpret the data obtained by means of electrical methods (as vertical electrical soundings, or ERT) performed in gypsum rocks. The development of an accurate protocol to measure the geoelectrical response of samples at the laboratory level is also the aim of the research, since the laboratory measurements would support the electrical resistivity ranges obtained by the theoretical and field methods.

\section{MATERIAL AND METHODS}

The geoelectrical classification has been elaborated comparing the resistivity values obtained from: 1) theoretical models; 2) laboratory tests; and, 3) field examples.

\subsection{THEORETICAL MODELS}

On the basis that gypsum rocks are formed essentially by gypsum mineral and enclosed lutites together with accompanying carbonates, quartz, celestite... (Fig. 1), a set of theoretical models has been elaborated, representing homogeneous gypsum deposits (Fig. 2). The RES2DMOD program has been used; this program calculates the electrical apparent resistivity 
pseudosection for a user-defined 2D underground model (Loke 2002). This program has been widely applied in order to simulate the acquisition of field data in a known medium (Cornacchiulo and Bagtzoglou 2004; Maillet et al. 2005; Srinivasamoorthy et al. 2009). Sumanovac et al. (2007) used RES2DMOD program to determine the resolution of a block model in a homogeneous mean. The models of this study are formed of a block of theoretical gypsum rock and a conductive background (with a resistivity of $1 \mathrm{ohm} . \mathrm{m}$ in order to facilitate the passage of electrical current). The model blocks are composed by 1760 small squares and each square has a value of 10 or $1000 \mathrm{ohm} . \mathrm{m}$ depending on whether it represents lutite or gypsum mineral. The size of the block was selected in order to be large enough to let the inversion achieve the values of the original model. The shape of a block was chosen at the expense of a continuous layer to support the absence of artifacts. The conductive mean which surrounds the model block has the lowest electrical resistivity value possible in order to optimize the sensitivity within the gypsum rock block.

The composition of the block has been changed for every model displaying different purities of the gypsum rock block from $0 \%$ to $100 \%$ (in gypsum mineral composition). These models represent the morphological distribution of the rock at the microscale for different purities. In the models, the scattered phase (meaning lutites) has been represented as small and homogeneously dispersed impurities within the model block. The sensitivity of the method is unable to distinguish these impurities; thus, the inversion of the data does represent the theoretical gypsum body as a homogeneous deposit.

The direct model pseudosections have been processed afterwards with the program RES2DINV which uses the smoothness-constrained least-squares method (deGroot-Hedlin and Constable 1990; Sasaki 1992; Loke 1996) in its inversion routine.

\subsection{LABORATORY TESTS}

Some laboratory tests were carried out by many authors in order to measure the electrical response of several geologic materials (Daily et al. 1995; Ewanic et al. 2001; Giao et 
al. 2003; Vanhala et al. 2009; Rusell and Barker 2010; among others). These authors mainly focused on the study of clays (and lutites) because of their relative low electrical resistivity values. The conductivity properties of different mineral crystals was also studied under laboratory conditions by Telkes (1950), Bleaney and Bleaney (1976), Orellana (1982) and Halpern (1998), giving a wide range of resistivity values. Nevertheless, the study of the electrical resistivity response of whole rocks or aggregates with medium-high resistivity is poorly developed. The electrical behaviour of bulk rocks or isolated mineral crystals is substantially different given that electrical current tends to spread along the contacts between the crystals and/or along the lowest resistive minerals (clays). In our research, the composition of different gypsum rocks with changing purities has been simulated in order to quantify the changes in the measured resistivity values. Nevertheless, because the laboratory conditions differ from those of the field (humidity, measuring scale, heterogeneities, etc.), it is to be expected that the resistivity values obtained would be slightly higher than those obtained in field conditions. This is principally because, at field scale, the electrical current can find some conductive paths to spread due to the anisotropy of the terrain while at a smaller scale the samples are more homogeneous, thus they could display a more resistive behaviour.

Several tests have been performed in laboratory conditions in order to measure the electrical resistivity response of gypsum rocks. Eleven sample-pills have been made with a mixture of different proportions of powdered clay and gypsum, simulating real geological samples, and an electrical current has been applied through them. The pills are made of mixed red clays (collected in the field) with pure dihydrated calcium sulphate (Panreac PA-ACS $\mathrm{CaSO}_{4} \cdot 2 \mathrm{H}_{2} \mathrm{O}$ laboratory reagent ref. 131235.1210 , simulating natural gypsum). The clays were dried in a furnace at $40^{\circ} \mathrm{C}$ for 2 days and powdered. The bulk and clay mineral composition of the clay fraction was studied by X-ray diffraction as randomly oriented powder and oriented preparations (air-dried, glycolated and heated at $550^{\circ} \mathrm{C}$ ) in a Siemens D-500 diffractometer. The clay-gypsum mixture varies from 0 to 100\% of gypsum (intervals of 10\%; Fig. 3). Each pill was prepared under overpressure conditions (press machine at $200 \mathrm{kN}$ ) for 60 seconds. In order to 
support the cementation of the pills, the blended powder-samples were slightly wetted with sprayed distilled water before the pressing process; otherwise the pills are brittle.

Additionally, the sample was hand-pressed with a whirling movement before connecting the press in order to distribute the sample homogeneously. After this process, the pills were left to dry for 48 hours. The resulting pills, $13.5 \mathrm{~g}$ in weight, took a cylindrical shape, $2 \mathrm{~cm}$ in radius. The thicknesses of the cylinders, measured with a vernier caliper, were around $0.5 \mathrm{~cm}$. The pills with higher gypsum purity are too resistive in order to be measured; thus other thinner pills, 3.5g in weight, were prepared for the purest gypsum samples (70, 80, 90 and 100\% of gypsum). The thickness of this second set of pills, also measured with the vernier calliper, was close to $0.15 \mathrm{~cm}$. With this thickness it is possible to measure the resistivity of the higher purity pills (reducing the distance between the poles).

An electrical circuit was developed under laboratory conditions in order to perform the measurements of the electrical resistivity of the pills (Fig. 4). The power source was a laboratory DC converter power supply (0 to $32 \mathrm{~V}$ ); the negative-pole wire incorporated a microammeter (0-100 microamps). The electrodes used on the samples are made of stickers with metallic buttons, in accordance with the UNE 21-303-33 regulation (1983). The button has a conductive gel in the sticking side, forming a $0.75 \mathrm{~cm}$-radius circled face (which will be considered the surface of the electrode). This gel is directly connected to the samples. These sticker-electrodes are connected to both sides of the samples in the same position (because the electrical current runs perpendicularly to the samples). The buttons of the electrodes are clamped by the pins of the wires which connect both poles of the circuit, with the sample acting as a resistance. The sample is laid upon an insulator made of paperboard to avoid electrical leakages. Measuring the current (I) at a known voltage (V), Ohm's law can be applied to calculate the resistance (R) of the sample (Eq. 1):

Equation.1

$$
I=\frac{V}{R}
$$


As the width (L) of the sample and the surface area of the electrode (S) are also known, the electrical resistivity ( $\rho$ ) value can be calculated (Eq. 2):

Equation.2:

$$
R=\rho \frac{L}{S}
$$

The sample measurements have been carried out at 10, 30, 60, 180 and 300 seconds. The readings were made with $2 \mathrm{~A}$ amperage and a voltage of $3 \mathrm{~V}$ or $32.2 \mathrm{~V}$.

\subsection{FIELD EXAMPLES}

A total of 7 ERT profiles (A, B, C, D, E, F and G) have been performed in different gypsum formations along the Ebro and Vallès-Penedès Basins and in the South Pyrenean Foredeep (North East Spain). The measurements of the apparent electrical resistivity have been made with a SYSCAL PRO switch with 48 electrodes separated by 10, 5, 2, 1 or 0.5 meters between them (depending on the investigation depth),using an internal power supply. Although many different arrays are used in electrical prospecting (Szalai and Szarka 2008), the selected arrays in our research were Wenner-Schlumberger and Dipole-Dipole, using the most suitable (depending the presence of structures with horizontal or lateral variations, respectively) in each case. The program used to carry out the inversion of the acquired data is RES2DINV as in the case of the theoretical models.

According to the solubility of gypsum of $2.4 \mathrm{~g} / \mathrm{l}$ (at normal conditions), the amount of non-gypsum minerals was quantified by dissolving $0.5 \mathrm{~g}$ of powdered gypsum samples (collected from the studied formations) in $250 \mathrm{ml}$ of distilled water; the solutions were shaken for 24 hours and subsequently filtered. The remnant after filtering corresponds to the nonsoluble impurities of the gypsum rock (lutites, carbonates, quartz, etc.), which can be quantified.

\section{RESULTS AND DISCUSSION}




\subsection{THEORETICAL MODELS}

Lutites are accompanying materials in gypsum lithofacies commonly; they are disseminated in the rock (solid inclusions within the gypsum crystals or in the intercrystalline porosity) or as separate lutite laminae or beds. The purity of gypsum deposits (percentage of gypsum minerals) can vary widely, even in the same evaporite unit. For deposits consisting of alternating laminated-to-banded levels with different purities (gypsum-lutites), the geoelectrical image would be generally interpreted as homogeneous bodies represented by the mean value of the deposit, alternating lithologies would - or would not - be identified after the inversion routine of the data depending on the thickness of the levels due to the sensitivity of the method. A set of theoretical models has been elaborated, representing an evaporitic deposit constituted of gypsum rocks with disseminated enclosing lutites (Fig. 2).

Into the initial user-defined model (Fig. 5A), the mean electrical value assigned to gypsum mineral was 1000 ohm.m and 10 ohm.m for lutites (essentially clay and marl), thus the real block-resistivity values for the two extreme cases of gypsum rock content of $0 \%$ and $100 \%$ is $10 \mathrm{ohm} . \mathrm{m}$ and $1000 \mathrm{ohm} . \mathrm{m}$, respectively. In the inversion of data we can iterate the program until it achieves these values at the point of the model block with highest resistivity value (reference point in Fig. 5C). The methodology used with the rest of the models (with purity from $10 \%$ to $90 \%$ ) consists of performing the same number of iterations and checking the resistivity value at the same point of the model block. This value would represent the electrical resistivity value for a gypsum rock with the purity selected on the initial model. Different arrays were tried during the elaboration of the models: Wenner alpha, inline Dipole-Dipole, Pole Dipole and Wenner Schumberger. These arrays are commonly used in geoelectrical surveys and they have different sensitivity distributions. Wenner-Schlumberger was the most stable between iterations when reaching the expected value in the reference models (100\% and $0 \%$ of purity). The electrode spacing selected was 2 meters, in order to have an adequate investigation depth for the models. With this procedure an apparent-resistivity pseudosection of the model was obtained (Fig. 5B). Afterwards, the data from the direct model were inverted. The inverted value 
of the resistivity section has been checked at the centre of the model (at a horizontal position of 47 meters and a depth of 9.60 meters) in different iterations (Fig. 5C). Between iterations 17 and 18, the value of resistivity reached 1000 ohm.m at this point $\left(994.45 \mathrm{ohm} . \mathrm{m}\right.$ in the $17^{\text {th }}$ iteration and 1022.40 ohm.m in the $18^{\text {th }}$ iteration, respectively). The obtained value is considered to be correct as we know that the original model block had a resistivity of 1000 ohm.m. In the case of the model with $0 \%$ purity, it displays a value of 12.15 ohm.m and 12.16 ohm.m in iterations 17 and 18 , respectively, which is also close to initially considered electrical resistivity value in the original model (10 ohm.m; Fig. 6).

The inverted resistivity values obtained for the reference point $X=47.00 \mathrm{~m}, \mathrm{Z}=-9.60 \mathrm{~m}$ in iterations 17 and 18 for the different purity models have been collected in order to relate them with the gypsum contents of the rocks. The trends in the plot of calculated resistivity from iterations 17 and 18 are almost coincident, and only slightly diverge in the $90 \%$ and $100 \%$ purity values (Fig. 6). Because of this, the mean trend between both lines can be considered. The results show three different transects: 1 ) Purity of the rock from $0 \%$ to $50 \%$; the plot shows a slightly increasing trend in the electrical resistivity values while increasing the purity. 2) Between 50 and $70 \%$ of gypsum purity; the value of resistivity increases exponentially. 3) Above to $80 \%$ of gypsum contents; the slope of the curve tends to diminish until the maximum resistivity value for pure gypsum rocks.

\subsection{LABORATORY TESTS}

Some different essays were carried out before the adequate development of the circuit device. The selected electrodes and the design of the circuit are in accordance with the UNE 21303-33 regulation, which states that the measures have to be done with a DC and stable current. Previous tests were performed within a wide range of voltage between 1 and $200 \mathrm{~V}$, taking into account that higher voltages could induce superficial secondary electrical currents and that the presence of any type of low resistivity impurities in the rock (as lutites) could overcharge the sample and generate small fractures. As it was observed that no leakages occurred within the 
range of 1-200 V, a guard-ring around the electrodes is not required. An amperage above $1 \mathrm{~A}$ in the power supply has been shown to be enough; the use of different amperage conditions higher than 1 A does not display different measures, thus an amperage of 2 A has been selected for the experiences.

Several gypsum-clay pills were measured. The amperage conditions of the power supply during the experience remained constant ( 2 A) and the measured amperage in the gypsum-clay pills varied from below $(<1 \mu \mathrm{A})$ to above $(>100 \mu \mathrm{A})$, the detection limits of the micro-ammeter. The two applied voltage conditions from the power supplies were $3 \mathrm{~V}$ and 32.2 $\mathrm{V}$. The results indicate that the lower one is most suitable for optimum measures in $0.5 \mathrm{~cm}$ thickness pills up to $70 \%$ gypsum content (Table 1); measures in gypsum-richer samples (higher than $70 \%$ ) were out of scale $(>100 \mu \mathrm{A})$. In order to study pills with purities higher than 70\% within the measure range of the ammeter, thinner pills (with a thickness around $0.15 \mathrm{~cm}$ ) were prepared. The sample measures in the laboratory circuit have been carried out at 10, 30, 60, 180 and 300 seconds. Measurements clearly tend to decrease at higher intervals of time and the fall is more sudden when increasing lutite contents (lower gypsum purity), due to the polarization of the enclosed clay minerals (Table 1, Fig. 7). The injected current is continuous and the terrain would not polarize supposedly; nevertheless, it is clearly shown that the samples with large clay composition tend to be polarized while increasing the reading time when the electrical current flows. The most polarized sample is the purest clay-pill (100\% clay) while polarization stops in a $60 \%$ gypsum, $40 \%$ clay mixture. It is considered that the optimum measuring time is 10 seconds, in order to be representative of the measures of the geoelectrical methods (as they do not inject a continuous electrical current during a long period of time).

The results of the laboratory tests show an increasing electrical resistivity value pattern clearly related to the gypsum-purity in the samples. The results from the measures can be divided into three transects (Table 1, Fig. 8): 1) The first transect corresponds to the measurements obtained in $0.5 \mathrm{~cm}$-thick pills up to approximately $50 \%$ in gypsum-purity. The absolute resistivity values obtained and the gypsum-purity vs resistivity pattern are very similar 
to those obtained after theoretical calculation (Fig. 6). The electrical resistivity value slightly increases from about 11ohm.m (0 \% gypsum) to 37 ohm.m (50 \% gypsum). 2) The second part is a transitional area between 1 and 3 (60 to $70 \%$, both included); the electrical resistivity values of the pills with a thickness of $0.5 \mathrm{~cm}$ increase rapidly but still inside the range of the micro-ammeter scale of measures. 3) The third part of the plot corresponds to the $0.5 \mathrm{~cm}$-thick richest-gypsum pills (>70 \%); the electrical resistivity values cannot be measured because they are below the detection limit (readings $<1 \mu \mathrm{A}$ ), while the poorest-gypsum samples show signals within the ammeter range.

As the voltage increase is not enough to obtain a measurement for the purest pills, the transect 3 has been completed by means of decreasing the thickness of the pills $(0.15 \mathrm{~cm})$ and applying $32.2 \mathrm{~V}$. In this case the micro-ammeter shows readings, the pill with $70 \%$ is above the scale of the micro-ammeter $(>100 \mu \mathrm{A})$, while the 80,90 and $100 \%$ purity pills show a clear increasing trend in the final calculated resistivity values, with the $100 \%$ pill being the most resistive.

The result from the X-ray diffraction of the powdered clay shows that it is composed of chlorite, kaolinite and illite with minor amounts of calcite, quartz, feldspars and gypsum. It has to be noted that, while the powdered clay fraction of the pills can be directly compared with the geological clay or lutite units, the powdered gypsum fraction is texturally and crystallographically different from the gypsum deposits. The $\mathrm{CaSO}_{4} \cdot 2 \mathrm{H}_{2} \mathrm{O}$ reagent used is cryptocrystalline (finely crystalline), while common gypsum rocks are from micro- to macrocrystalline (up to several meters in the largest selenite crystals). Thus, these values cannot be considered to be representative of real gypsum rocks.

\subsection{FIELD EXAMPLES}

Several gypsum formations along the South Pyrenean Foredeep, Ebro and VallèsPenedès Basins (NE Spain; Fig. 9) have been studied. These examples are presented below (from higher to lower gypsum purity): 
(A) South Pyrenean Foredeep: A thick evaporitic marine deposit took place during the Lutetian (Middle Eocene) in the eastern Pyrenees (Rosell and Pueyo 1997). Anhydrite (and halite) rocks have been described at depth in boreholes (Carrillo 2009), while secondary gypsum (coming from the hydration of anhydrite) is found in outcrops; the evaporite body is mainly constituted of graynish banded to massive microcrystalline gypsum. Close to the village of Sant Joan les Fonts (Girona province), gypsum rocks outcrop between clay levels (Fig. 10A), attributed to the Beuda Gypsum Unit (Carrillo 2009). The measured purity of a gypsum sample is $98 \%$ gypsum. An ERT profile has been carried out near the outcrop in order to evaluate the electrical response of the gypsum-pure layer. The ERT line (Fig. 11A) shows a 5 m thick resistive body, with a mean value of electrical resistivity around 1000 ohm.m, which clearly corresponds to the purest evaporite layer (layer A in Fig. 12A).

(B) Vallès-Penedès Basin: During the evolution of the Vallès-Penedès Basin, several transgressive pulses in the Burdigalian (Early Miocene) led to partial flooding of the western part of the basin and promoting the precipitation of the Vilobí Gypsum Unit (Ortí and Pueyo 1976; Bitzer 2004). At the western part of the Vilobí del Penedès village (Barcelona province), extensive extraction took place in the last century. The deposit is mainly constituted of banded gypsum alternating with thin lutite-carbonate laminae (Fig. 10B); scarce nodular-entherolithic lithofacies are also recognized. Outcropping gypsum is micro- to macrocrystalline (up to several centimeters in length) secondary (coming from the hydration of anhydrite). The mean gypsum mineral content from the exploited rocks had a purity of 85-87\% (personal communication from the chemistry technician of the exploitation body, 2009), while our analyzed gypsum sample displayed a slightly higher purity (92\%). The ERT profile (Fig. 11B) permits us to interpret the presence of an overlying clay level, offering a low electrical resistivity values (around 10 ohm.m), and a shallow body with intermediate resistivity corresponding to calcarenite layer (which outcrops close to the studied area). The top of the gypsum body is identified at $13 \mathrm{~m}$ depth (level B in Fig. 12B), showing higher resistivity values (between 700 and 1000 ohm.m). There is a low resistive structure between the two main gypsum bodies (Fig. 11B). 
(C) Catalan margin of the Ebro Basin: The SE of the Catalan margin of the Ebro Basin recorded during the Eocene-Oligocene several evaporitic lacustrine events (Ortí et al. 2007). Guinea et al. (2010) studied the Pira Gypsum, nearby the village of Pira, by means of 8 ERT profiles and a borehole (Tarragona province), in the Conca de Barberà sector of the Ebro Basin. The gypsum-rock body was suitably described and a relation between the purity of the gypsum and the electrical resistivity value was established but not quantified. The measured gypsumpurity from the selected core samples were: $92-94 \%$ for the purest levels, $56 \%$ for the impurest levels and some from 65 to $72 \%$ in the thin-gypsum embedded in a lutite body (Guinea et al. 2010). Gypsum layers in this outcrop are constituted of microcrystalline reddish to greenish secondary gypsum, massive to diffusely banded-laminated; nodules of pure white microcrystalline (alabastrine) gypsum are enclosed in the gypsum mass (Fig. 10C), which were extensively exploited as sculpture alabaster for ornamental purposes since the fourteenth century and up to the 1970s. The ERT image (Fig. 11 C) shows a layer (0.9 m depth) with an electrical resistivity value of $1000 \mathrm{ohm} . \mathrm{m}$, corresponding to the C-1 layer (Fig. 12C); the resistivity decreases rapidly, reaching 50 ohm.m in the underlying sediments (C-3 layer, Fig. 12C). This value is probably slightly higher than the real value because it is displayed at the bottom of the profile, where the method has the lowest sensitivity. The transition between the impure gypsum layer and the bottom values are bounded to the gypsum bearing lutites (C-2 layer, Fig. 12C).

(D) Catalan margin of the Ebro Basin: The Talavera Gypsum Unit was registered in the Catalan margin of the Ebro Basin during a pulse of lacustrine evaporitic precipitation (lowermost Oligocene; Ortí et al. 2007); several gypsum levels are intercalated in alternation with grey lutites and marls. The study has been carried out near to the village of Briançó (Cervera area, Lleida province). During the construction of the highway some nearby hills exposed the sedimentary deposit; the ERT profile was performed on the top of a hill. The evaporite sequence is made of laminated-banded and nodular secondary gypsum layers (few centimeters to $2 \mathrm{~m}$ thick) alternating with levels more lutitic (under $1 \mathrm{~m}$ thick, Fig. 10D). The 
two collected and analyzed samples indicate that gypsum content varies between $68 \%$ and $75 \%$, thus, the mean purity of the deposit is around $70 \%$ in gypsum content. The electrical imaging displays a quite homogeneous body with an electrical resistivity value between 150 and 500 ohm.m, in accordance with the outcropping unit (Fig. 11D, layer D in Fig. 12D). The homogeneity is due to the sensitivity of the method, which is not capable of distinguishing the different levels. A low resistive anomaly is placed in the right part of the ERT line, which can be interpreted to lateral changes in the sedimentary structures. The increasing of the resistivity values in the bottom of the profile probably reveals the presence of a purer gypsum body (not outcropping in the studied wall).

(E) Catalan margin of the Ebro Basin: The La Guàrdia Gypsum Unit is located stratigraphycally below the Pira Gypsum Unit (Ortí et al. 2007), introduced above, and thus belonging to the same geological setting. The upper part of this unit crops out to the north of the La Guàrdia de Prats village (Tarragona province), where it consists of reddish gypsum layers, less than $4 \mathrm{~m}$ thick in general, which have been the subject of small exploitations, alternating with metric to decametric lutite (and conglomerate) bodies. The lutite layers occasionally are cut by horizontal to about $45^{\circ}$ dipping satin spar gypsum veins (cements of fibrous gypsum in veins); visually estimated gypsum content of these lutite levels is around $10 \%$. The sequence has four levels which are from bottom to top (Fig. 10E): A) High purity microcrystalline to nodular secondary gypsum body; B) Lutite layer with gypsum veins of $2 \mathrm{~m}$ thick, corresponds to E-2 layer (Fig. 12E); C) Massive to nodular microcrystalline secondary gypsum layer with a measured purity of $73 \%$ and 1 to $2 \mathrm{~m}$ thick, corresponds to E-1 layer (Fig. 12E); D) 2-3 m of quaternary reddish deposit. An ERT profile has been carried out in this area (Fig. 11E), which displays a set of values ranging from 200 to 500 ohm.m for the E-1 gypsum layer (72\% of gypsum content). The structure of the E-2 layer with gypsum veins is not well defined in the profile; the measures have been affected by the most resistive layers above and below (which increases the real resistivity value), but in any case this body displays a range of values from 30 to $100 \mathrm{ohm} . \mathrm{m}$, the expected value is around $10 \mathrm{ohm} . \mathrm{m}$ for this level with veins. 
(F) Catalan margin of the Ebro Basin: The profile F (Fig. 11F) has been performed 500 meters far from the profile E, thus also prospecting La Guàrdia Gypsum Unit (Ortí et al. 2007). The profile has been carried out directly over a 2 m-thick lutite layer cut by satin spar (Fig. 10F), overlying a gypsum body. The electrical imaging (Fig. 11F) shows a body with $10 \mathrm{ohm} . \mathrm{m}$ of electrical resistivity value which is interpreted to correspond to the gypsum-rich lutite level (layer $\mathrm{F}$ in Fig. 12F). Below this body the resistivity value increases until 1000 ohm.m, corresponding to the higher gypsum-purity body.

(G) Ebro Basin: During the construction of the Spanish high velocity train (AVE) railways, some boreholes crossing the Zaragoza Gypsum and Anhydrite Formation were performed in the area of the Montes de Torrero (Zaragoza province). This Miocene formation, hundreds of $\mathrm{m}$ thick, was deposited in the Aragón sector of the Ebro basin; it is mainly constituted of anhydrite, glauberite and halite at depth (also thenardite in small quantities), while gypsum is the main evaporite mineral in exposed areas sulphates; the presence of marl and clay is ubiquitous (Ortí 2000; Salvany 2009). Impure secondary gypsum rocks coming from anhydrite or glauberite hydration were cut by the boreholes. The $35 \mathrm{~m}$ of the B4 borehole cut an impure gypsum body, similar to the outcropping materials (Fig. 10G), with and estimated gypsum content of 20-40\%. The ERT profile (Fig. 11G) shows low electrical resistivity values for this gypsum impure layer (10-20 ohm.m; layer G in Fig. 12G). The secondary gypsumglauberite contact is at $35 \mathrm{~m}$ depth in the B4 borehole; nevertheless, the abundant presence of lutite in the glauberite deposit (also accompanied by anhydrite at depth) masks the resistivity response of such anhydre evaporites and tends to decrease the values, thus being similar to those of the impure gypsum rocks (Guinea et al. 2009).

\section{GEOELECTRICAL CLASSIFICATION OF GYPSUM ROCKS}

Theoretical, laboratory and field data have been obtained; they show three differentiated trends (Fig. 13): 
1) The first trend of resistivity values are from 0 to approximately $55 \%$ gypsum purity (obtained from interpolation; part 1 in Fig. 13). The electrical resistivity value increases from 10 (in the impurest member) to approximately 50 ohm.m (55\% of gypsum content), in accordance with the expected resistivity for lutites. In the case of the field examples, some rocks bodies placed within this range of purity show electrical resistivity values slightly higher (but below $100 \mathrm{ohm} . \mathrm{m}$ ). This is due to the position of these layers below a resistive material and/or located at depth (bottom of the ERT profile), where the sensitivity of the method is lower and then the values obtained are less reliable (layers C-3 and E-2 in the profiles C and E, respectively).

2) The second trend ranges from 55 to $75 \%$ (obtained from interpolation, these values are approximate) in gypsum purity and is characterized by an important resistivity values variation with little composition change (part 2 in Fig. 13), where the electrical resistivity increases exponentially, and ranging from 100 to $700 \mathrm{ohm} . \mathrm{m}$.

3) The third trend ranges from 75 to $100 \%$ in gypsum purity (part 3 in Fig. 13). The electrical resistivity value increases continuously with the increasing of the purity and offers a range of values of $700-1000$ ohm.m (from the impurest to the purest, respectively). In the case of the laboratory pill measurements, the values obtained are substantially higher than those obtained in both theoretical calculations and field measures, which is due to the crypto- to microcrystalline nature of the pills, in contrast to the micro- to macrocrystalline textures of the gypsum rocks. This type of gypsum is considered as economically profitable when displaying values of electrical resistivity above 800 ohm.m ( $80 \%$ in purity).

The existence of these three differentiated trends would be bound to the connection between lutite particles within the gypsum rock. In the case of the impurest members, the electrical current avoids the gypsum crystals, and preferentially flows along the lutite matrix (due to its conductive nature; Fig. 14A). The resistivity value slightly increases with increasing 
gypsum content in lutite bodies; nevertheless, the influence of these disseminated gypsum particles is scarce, and the lutite presence is the main controlling factor in their geoelectrical response. When the gypsum-purity achieves the minimum value to obtain a gypsum supported rock (corresponding to the packing coefficient of a simple cubic packing -52\%-; Fig. 14B) the electrical current is forced to pass through the gypsum crystals, even with a partially connected lutite matrix. This represents the boundary between transects 1 and 2. Increasing the purity of the rock, would achieve the packing coefficient of compact cubic package (74\%), which would correspond to a gypsum crystals supported texture $(78 \%$ intercrystalline porosity in a $2 \mathrm{D}$ representation; Fig. 14C). In this package, the lutite particles are no connected but scattered; thus the electrical resistivity measurements are dominated by the presence of the gypsum crystals. Figure 14C represents the transition between transects 2 to 3 in Fig. 13. In the purest gypsum rocks ( $>75 \%$ approximately; part 3 of Fig. 13) the resistivity increase tends to become stable; the electrical current is forced to flow through the gypsum crystals (Fig. 14D), probably by water.

A general classification of gypsum rocks on the basis of their geoelectrical response and purity has been defined (Table 2); three types of gypsum rocks are distinguished corresponding to the three different trends shown in the figure 13: 1) Pure gypsum, displaying an electrical resistivity response from 700 to 1000 ohm.m and $>75 \%$ in gypsum mineral. 2) Transitional (dirty) gypsum; belonging to the transition zone with about 75 to $55 \%$ in gypsum mineral composition and a range of electrical resistivity value from 100 to 700 ohm.m. 3) Lutites and rich-gypsum lutites; having a large amount of lutites on their composition (higher than 45\%), and showing an electrical resistivity range of values between 10 and $100 \mathrm{ohm} . \mathrm{m}$. The general trend of the electrical resistivity of gypsum rocks depending of their compositions is shown in Figure 15. This trend is based in the general tendencies observed in field, theoretical calculations and laboratory measurements (disregarding the pills with gypsum purity above of $70 \%$ because they have been considered not to be representative). This trend could be taken as a 
reference in future surveys in this type of rocks. The results are limited by the sensitivity of the method used, as in other surveys.

\section{CONCLUSIONS}

The geoelectrical response of gypsum rocks has been determined by comparing the resistivity values obtained from theoretical models, laboratory tests and field examples. The set of theoretical models, representing several gypsum deposits with different compositions, provide evidence of a clear relationship between the lithological composition of the whole rock and its electrical resistivity.

The relationship between the gypsum content and electrical resistivity has been quantified in several laboratory tests, by means of measuring 11 artificial pills (mixtures of different clay/gypsum proportions). The measurements show evidence for similar absolute resistivity values to those of the theoretically calculated in the models, and display two inflexion points at the same composition ranges. Nevertheless, the resistivity of the purest pills is higher than in the geological pure gypsum rocks, due to textural differences between the cryptocrystalline nature of the pills. The connectivity between the lutite particles is the main controlling factor in their geoelectrical response.

The electrical resistivity values interpreted in the different field tomography profiles are consistent with the theoretical calculations and the laboratory tests carried out in the pills with purities below $80 \%$ in gypsum.

A geoelectrical classification of gypsum rocks defining three types of gypsum rocks has been generated: a) Pure Gypsum Rocks (>75 \% of gypsum content with an electrical resistivity value of 700-1000 ohm.m), b) Transitional Gypsum Rocks (75-55 \% of gypsum content with an electrical resistivity value of 100-700 ohm.m), and c) Lutites and Gypsum-rich Lutites (<55\% of 
gypsum content with an electrical resistivity value of 10-100 ohm.m). The Transitional Gypsum rocks would represent the transition between the clay supported and gypsum supported textures.

Pure Gypsum Rocks have industrial interest (with an electrical resistivity value $>800$ ohm.m); thus geoelectrical techniques can be applied to determine the availability of a gypsum deposit to be exploited.

The methodology used could be applied in other geoelectrical rock studies, given that this relationship between the resistive particles embedded within a conductive matrix depends on the connectivity of the matrix particles.

\section{ACKNOWLEDGEMENTS}

The present work is part of a $\mathrm{PhD}$ Thesis supported by the "Programa General de Intensificació de la Investigació 2008-2011” (Generalitat de Catalunya-UB) and the Spanish Government Projects CGL2009-11096, CGL2009-07025 and CGL2010-18260. We want to appreciate the support and facilities of Dr. Albert Casas from the University of Barcelona. We also want to appreciate the comments of the reviewer and of the Editor in Chief, which have helped us to improve the manuscript.

\section{REFERENCES}

Bitzer K (2004) Estimating paleogeographic, hydrological and climatic conditions in the upper Burdigalian Vallès-Penedès basin (Catalunya, Spain). Geologica Acta 2:321-331

Bleaney BI, Bleaney B (1976) Electricity and Magnetism 3rd Edition. Great Britain: Oxford University Press, pp 63 
Bonetto S, Fornaro M, Giulani A, Lasagna M (2008) Underground quarrying and water control: Some cases from Nothern Italy. 10th International Mine Water Association Congress, 2008, Czech Republic, Expanded Abstracts: P02

Carrillo E (2009) Unidades evaporíticas eocenas de la Zona Surpirenaica Oriental (Área de La Garrotxa). Geogaceta 47:73-76

Cerulla J (1997) Extracción, explotación, minería y proceso de tratamiento del yeso. Boletín de la Sociedad Española de Cerámica y Vidrio 36:571-577

Cornacchiulo D, Bagtzoglou AC (2004) Geostatistical Reconstruction of Gaps in NearSurface Electrical Resistivity Data. Vadose Zone Journal 3:1215-1229

Daily W, Ramirez A, LaBrecque D, Barber W (1995) Electrical resistance tomography experiments at the Oregon Graduate Institute. Journal of Applied Geophysics 33:227-237

deGroot-Hedlin C, Constable S (1990) Occam's inversion to generate smooth, twodimensional models from magnetotelluric data. Geophysics 55:1613-1624

Ewanic M, Reichhardt D, Brunet BS (2001) Electrical Resistivity Tomography Imaging of a Colloidal Silica Grout Injection. Containment Remediation Technology, Abstract: 137

Giao PH, Chung SG, Kym DY, Tanaka H (2003) Electric imaging and laboratory resistivity testing for geotechnical investigation of Pusan clay deposits. Journal of Applied Geophysics 52:157-175

Guinea A, Playà E, Rivero L, Salvany JM, Himi M (2009) Geoelectrical imaging supporting glauberite deposits evaluation in the Montes de Torrero area (Zaragoza). Geogaceta $47: 145-148$ 
Guinea A, Playà E, Rivero L, Himi M (2010) Electrical Resistivity Tomography and Induced Polarization techniques applied to the identification of gypsum rocks. Near Surface Geophysics 8:249-257

Halpern A (1998) Schaum's Outlines Beginning Physics II. New York: McGraw-Hill Companies Inc., pp 141

Loke MH, Baker RH (1996) Rapid least-squares inversion of apparent resistivity pseudosections by a quasi-Newton method. Geophysical Prospecting 44:131-152

Loke MH (2002) RES2DMOD ver 3.0. 2D Resistivity and IP Forward Modelling. Ed. M. H. Loke Penang

Lugo E, Playà E, Rivero L (2008) Aplicación de la tomografía eléctrica a la prospección de formaciones evaporíticas. Geogaceta 44:223-226

Martinez J, Benavente J, García-Arostegui JL, Hidalgo MC, Rey J (2009) Contribution of electrical resistivity tomography to the study of detrital aquifers affected by seawater intrusion-extrusion effects: The river Vélez delta (Vélez-Málaga, southern Spain). Engineering Geology 118:161-168

Maillet GM, Rizzo E, Revil A, Vella C (2005) High resolution electrical resistivity tomography (ERT) in a transition zone environment: Application for detailed internal architecture and infilling processes study of a Rho^ ne River paleo-channel. Marine Geophysical Researches 26:317-328

Norma española UNE 21-303-83 (1983) Métodos para la medida de la resistividad transversal y superficial de los materiales aislantes eléctricos sólidos. Instituto Español de Normalización

Orellana E (1982) Prospección geoeléctrica en corriente continua. Paraninfo, pp 523 
Ortí F, Pueyo JJ (1976) Yeso primario y secundario del depósito de Viloví (provincia de Barcelona, España). Instituto de Investigaciones Geológicas 31:5-34

Ortí F (2000) Unidades glauberíticas del Terciario ibérico: nuevas aportaciones. Revista de la Sociedad Geológica de España 13:227-249

Ortí F, Rosell L, Playà E (2007) Depositional models of lacustrine evaporites in the SE margin of the Ebro Basin (Paleogene, NE Spain). Geologica Acta 5(1):19-34

Ortí F, Rosell L, Playà E, García-Veigas J (2010-in press) Large gypsum nodules in the Tertiary evaporites of Spain: distribution and paleogeographic significance. Geological Quarterly 54(4)

Regueiro M, Marchán C (2004) La industria española de las rocas y minerales industriales. Rocas y minerales 392:64-80

Rosell L, Pueyo JJ (1997) Second Marine Evaporitic Phase in the South Pyrenean Foredeep: The Priabonian Potash Basin (Late Eocene: Autochthonous-Allochthonous Zone). In: Busson G, Schreiber Ch (Eds) Sedimentary deposition in rift and foreland basins in France and Spain. Columbia University Press, New York, 358-387

Rusell EJF, Barker RD (2010) Electrical properties of clay in relation to misture loss. Near Surface Geophysics 8:173-180

Salvany JM (2009) Geología del yacimiento glauberítico de Montes de Torrero (Zaragoza). Prensas Universitarias de Zaragoza, pp 72

Sasaki Y (1992) Resolution of resistivity tomography inferred from numerical simulation. Geophysical Prospecting 40:453-46 
Srinivasamoorthy K, Sarma VS, Vasantavigar M, Vijayaraghavan K, Chidambaram S, Rajivganthi R (2009) Electrical imaging techniques for groundwater pollution studies: a case study from Tamil Nadu state, South India. Earth Sciences Research Journal 13:30-39

Sumanovac F, Dominkovic S (2007) Determination of resolution limits of electrical tomography on the block model in a homogenous environment by means of electrical modelling. Rudarsko-Geolosko-Naftni Zbornik 19:47-56

Szalai S, Szarka L (2008) On the classification of surface geoelectric arrays. Geophysical Prospecting 56:159-175

Telkes M, (1950) Thermoelectric power and electrical resistivity of minerals. American Mineralogist 35:536-555

Vanhala H, Lintinen L, Ojala A (2009) Electrical Resistivity Study of Permafrost on Ridnitšohkka Fell in Northwest Lapland, Finland. Geophysica 45(1-2):103-118 


\section{FIGURE CAPTIONS}

Figure 1: Photomicrograph (plane polarized light) of different gypsum rocks showing A) pure gypsum, $B$ ) impure gypsum and $C$ ) gypsum-rich lutites.

Figure 2: Model blocks elaborated with the RES2DMOD program; each block represents a gypsum rock body with changing composition (gypsum versus lutite percentages).

Figure 3: Sample pills made using mixtures of powdered clays and $\mathrm{CaSO}_{4} \cdot 2 \mathrm{H}_{2} \mathrm{O}$ laboratory reagent in different proportions (100\% to $0 \%$ gypsum contents in intervals of $10 \%)$.

Figure 4: Electrical circuit developed to measure the electrical resistivity values of the pill samples; it consists of a switchable laboratory power-supply, two electrodes and a microammeter.

Figure 5: Sketch of the theoretical calculation process, showing a model-block representing a 100\% pure gypsum rock (A). From the theoretical model an apparent resistivity value pseudosection is calculated $(B)$ and afterwards the data are inverted by performing $17-18$ iterations. The value of the calculated resistivity is checked at a reference point $(C)$, which must have the same value as that of the initial model. The process is repeated with different model blocks with initially unknown bulk electrical resistivity values.

Figure 6: Electrical resistivity values calculated from the theoretical models from gypsum bodies, with purity ranging from 0 to $100 \%$. The values show the difference in the calculation between the iterations 17 and 18. The three different transects of resistivity are displayed in the background with different colours.

Figure 7: Plot showing the relationship between the measured amperage and the time of measurement for different gypsum content in the samples. 
Figure 8: Semi-logarithmic plot representing the results of electrical resistivity laboratory measures in pills. The graph has been made using measurements on $0.5 \mathrm{~cm}$ thick pills at $3 \mathrm{~V}$ for purities lower than $80 \%$ and on $0.15 \mathrm{~cm}$ thick pills at $32.2 \mathrm{~V}$ for the purest samples.

Figure 9: Distribution of evaporite formations in the Tertiary basins of central and northern Spain indicating the location of the seven studied ERT profiles (modified from Ortí et al., 2010, in press).

Figure 10: Photographs of the different studied areas displaying the different purities of the gypsum rocks in which the ERT profiles were performed. A) Pure gypsum outcrop (A) in Sant Joan Les Fonts village (Girona). B) Laminated pure gypsum (B) in Vilobí del Penedès village (Barcelona). C) Uppermost part of the gypsum deposit (C-1) of Pira village (Tarragona) showing the purest layers. D) Alternation of different intermediate-high purity layers (D) of gypsum in Cervera village (Lleida). E) Intermediate-high gypsum layer (E-1) and lutite layer with satin spar gypsum veins within (E-2) in La Guàrdia de Prats village (Tarragona). F) Lutite layer with gypsum veins within (F) in La Guàrdia de Prats village. G) Impure gypsum deposit (G) in the Montes de Torrero area (Zaragoza). The labels in the photographs represent the layers described in figures 11 and 12; the situation of the outcrops is shown in figure 8.

Figure 11: Inverted data of the electrical resistivity tomography lines for the different areas studied ( $A$ to $G$, same location and profiles than in figures 8 and 9). Profile $C$ slightly modified from Guinea et al. (2010).

Figure 12: Lithological interpretation of the ERT profiles ( $A$ to $G$, same location and profiles as in figures 8, 9 and 10).

Figure 13: Integrated plot combining the results of theoretical calculations, laboratory tests and the ranges of purity and electrical resistivity values measured in the field examples. The values obtained from the laboratory experiences were measured in the $0.5 \mathrm{~cm}$ thick pills at $3 \mathrm{~V}$. 
Figure 14: Two-dimensional simplified representation of the electrical current circulation through different gypsum rocks. A to $D$ sketches represent different gypsum contents in the rocks, from 15 to $90 \%$, respectively.

Figure 15: General electrical resistivity value trend of gypsum rocks, depending of their composition.

\section{TABLE CAPTIONS}

Table 1: Results of the laboratory measurements, depending on the time of measurement, the applied voltage and the thickness of the samples. The electrical resistivity value is calculated from the measurements performed at 10 seconds.

Table 2: Geoelectrical classification of gypsum rocks, depending on their gypsum purities. 


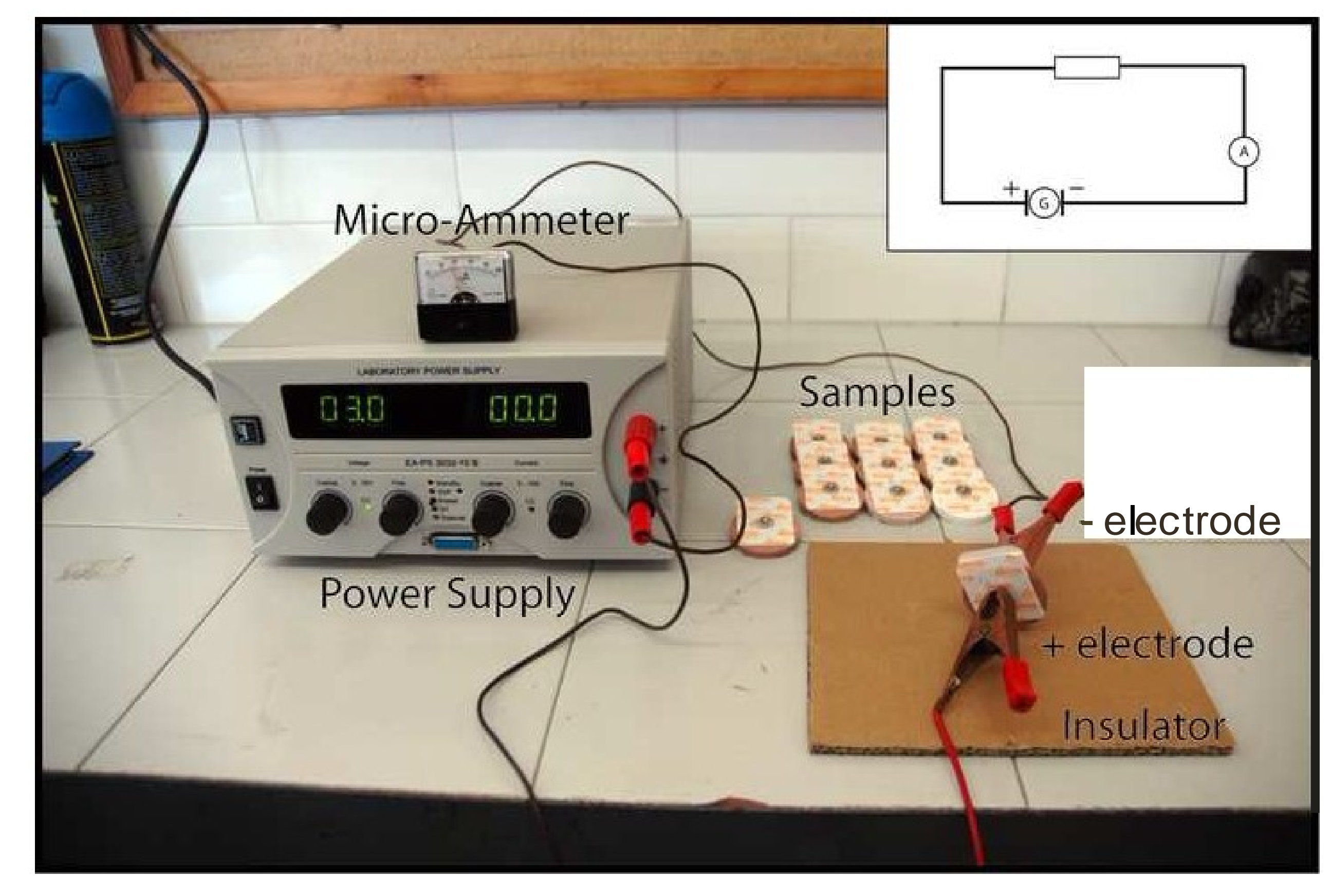


Dear editor of Surveys in Geophysics journal:

I submit you the manuscript entitled "Geoelectrical classification of gypsum rocks" revised. We agree with the corrections in the language performed by the reviewer. Also, the figure 4 now shows Micro-Ammeter instead of Micro-Amperimeter, as asked.

Regarding this, I noticed that in the text (Page 7, paragraph $3,4^{\text {th }}$ line) the microammeter was also mentioned as micro-amperimeter. Thus, I have corrected it in accordance with the correction of the Figure 4.

The references have been checked carefully and some small errors have been detected (as a couple of dots out of place). I hope they are right now.

As demanded, the whole text is submitted in black colour.

Thanks again, yours sincerely

Ander Guinea and co-authors

University of Barcelona 